\title{
Optimum design and control of grid integrated electrical hubs considering lifecycle cost and emission
}

\author{
A.T.D. Perera, Dasaraden Mauree, Jean-Louis \\ Scartezzini \\ Solar Energy and Building Physics Laboratory (LESO-PB), \\ Ecole Polytechnique Fédérale de Lausanne (EPFL), CH-1015 \\ Lausanne, Switzerland.
}

\author{
Vahid M. Nik \\ Division of Building Physics, Department of Building and \\ Environmental Technology, Lund University, Lund, Sweden.
}

\begin{abstract}
Grid connected renewable energy systems are becoming popular due to reasons such as rapid escalation of energy prices, depletion of fossil fuel resources and pollutant emitted by conventional energy sources. Therefore, technologies for incorporating renewable energy technologies into the existing electricity grid needs to be researched more considering the changes in grid architecture. This study presents a novel method for optimum design and control of an Electric-Hub (EH) which consist of Solar PV panels, wind turbines, battery bank operating in a grid (low voltage) integrated mode. This study reports the simulation based optimization algorithm developed to obtain optimum system configuration and operation strategy considering two conflicting objectives; i.e. Levelized Energy Cost (LEC) and Leveliyed CO2 emission (LCO2). A detail energy flow model is developed to evaluate energy flow through wind turbines and SPV panels on hourly basis. Interaction with the battery bank and the Low-Voltage Grid (LVG) is determined using an expert system. Operating state of the system is determined based on renewable energy generation, Cost of Electricity (COE) in the LVG, state of charge of the battery bank. Subsequently, operating states of the expert system and configuration of the EH; i.e. type and capacity of SPV panels, wind turbines and battery bank is optimized using steady state \&-multi objective optimization technique. Seven Pareto solutions are selected at the end and analyzed the system configuration and control strategy.
\end{abstract}

Index Terms-- Electrical Hub, Evolutionary Algorithms, Energyeconomic Dispatch, Multi Objective Optimization.

\section{INTRODUCTION}

Integrating renewable energy technologies into energy systems is becoming popular due to various reasons. Nondispatchable energy sources such as wind energy and Solar PV energy (SPV) is becoming more promising in this context especially due to the recent improvement in technology which resulted in higher energy conversion efficiency and lower cost in manufacturing. However, integration of nondispatchable energy technologies into grid has become challenging due to the stochastic nature of wind and solar energy [1]. Although higher penetration level of solar and wind energy is expected based on monthly or annual average data the scenarios notably change when moving to hourly scale considering stochastic nature of the demand and potential of these energy sources [2].

The concept of grid tied hybrid energy systems [3], [4], virtual power plants and electrical hubs [5] are presented to address the aforementioned challenges in designing energy system. Architecture of these energy systems looks quite similar to each other. This study focuses of an electrical hub a simplified version of multi energy hub considering only the electrical interactions. The electrical hub used in this study consists of non-dispatchable energy sources, energy storage connected to main utility grid (Figure 1).

Design optimization of electrical hubs combining several energy sources, storage and grid is a challenging task. Configuration of the system and energy flow needs to be considered when designing the energy system. Hence, simultaneous optimization of energy system and dispatch strategy should be performed [6]. A number of studies have been focused on designing hybrid energy systems for standalone applications without grid interactions [7]-[9]. Both mono and multi objective optimizations have been conducted considering multiple objectives [10]-[13]. However, energy flow within the system becomes more complicated with grid interactions especially when considering Real Time Pricing (RTP) of the grid and curtailments for grid interactions.

Methods used for designing standalone energy systems have been directly extended to evaluate grid integrated hybrid energy systems such as electrical hubs without properly addressing the grid curtailments and RTP in most of the instances. Agustín and Lopez [14] introduced an optimization algorithm to optimize capacity of wind power plant along with energy storage considering RTP and grid curtailments. However, catering a demand is not considered in this work. Ref. [15] presents optimum design of energy storage to cater an industrial demand with real time pricing of the grid. 


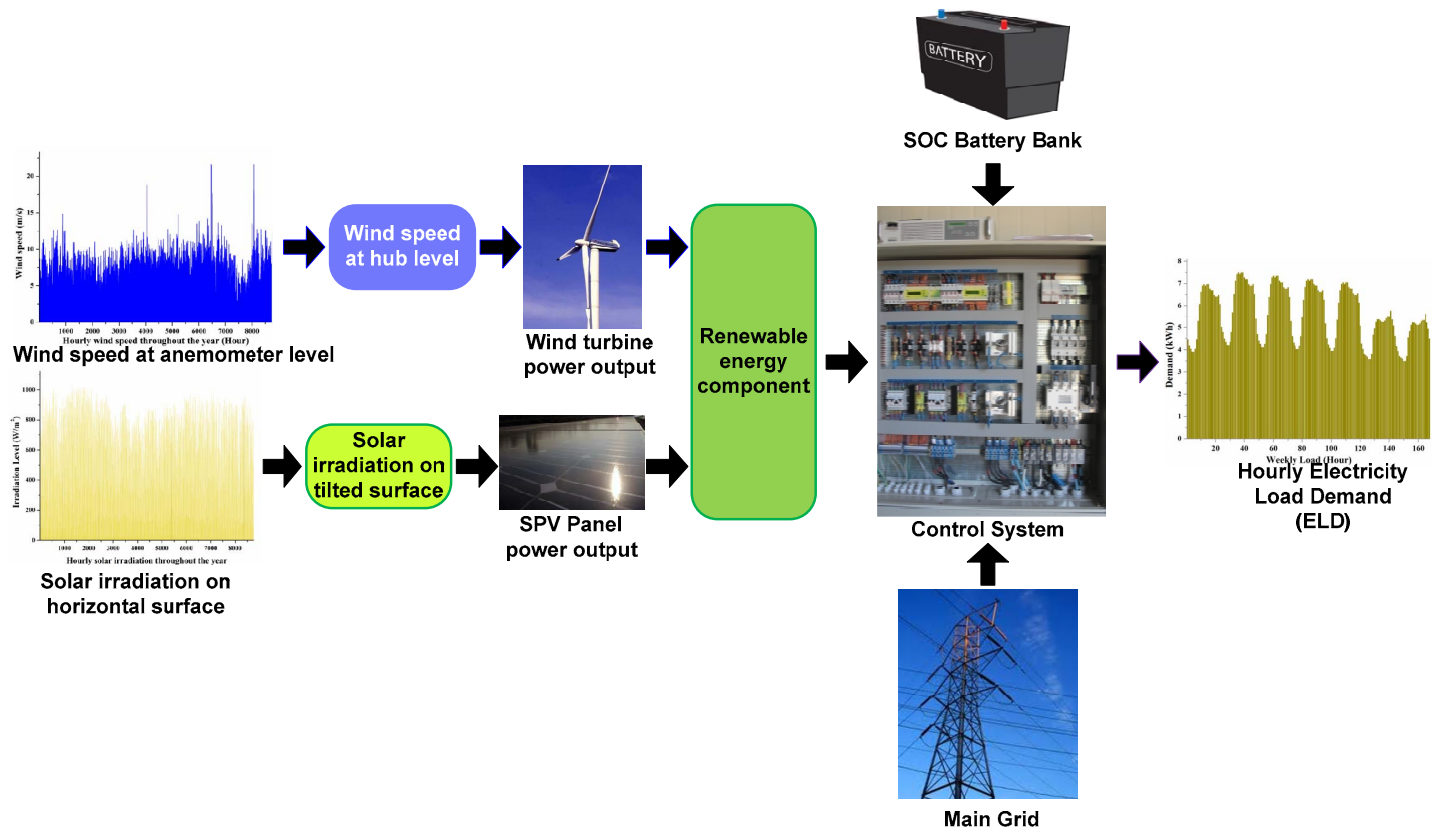

Figure 1. Brief overview of the energy system

Mavromatidis et-al [5] discusses about design of electrical hubs incorporating non-dispatchable energy and energy storage but RTP of grid is not considered in the optimization algorithm. This study introduces a novel method to optimize an electrical hub (Fig. 1) by addressing all the aforementioned limitations. In addition, Pareto multi objective optimization is conducted considering Levelized Energy Cost (LEC) and Levelized CO2 (LCO2) emission to assess economic and environmental aspects simultaneously.

\section{OVERVIEW OF COMPUTATIONAL MODEL}

The computational model developed in this study considers energy flow, cash flow and LCO2 of the system. Hourly solar irradiation on horizontal plane is taken from meteorological databases which are used to calculate the solar irradiation on tilted SPV panel using an anisotropic model. Durish model [16] is used to calculate the efficiency of SPV panels on hourly basis considering, solar irradiation, air mass and cell temperature. The number of SPV panels and the type of SPV panel are optimized using the optimization algorithm. Depending on the type and the capacity, initial capital cost is calculated for SPV panels. A fixed operation and maintenance cost is assigned for SPV panels $(5 \%$ of the initial cost) when calculating the lifecycle cost.

Similar to SPV panels, hourly wind speed data are taken from meteorological databases for Humbamtota, a coastal city in Sri Lanka. Power law is used to convert the wind speed at anemometer height into hub level wind speed. Power curve presented by manufacturer is used along with the cubic spline interpolation technique [17] to present the power curve of the wind turbine. Similar to SPV panels, the type of wind turbine used for the design and the number of wind turbines are optimized using the optimization algorithm. Life cycle cash flow for wind turbines are calculated in a similar way to SPV panels.

State of charge (SOC) model is used to evaluate the charge level of the battery bank. Rain flow algorithm [18] is used to calculate the lifetime of the battery bank. A detailed description about the models used to present different energy conversion processes can be found in Ref. [19]-[21]

Energy interactions with the utility grid were limited for both purchasing and selling electricity. $\mathrm{TG}_{\mathrm{lim}}$ is introduced as the upper bound for selling electricity to the grid which is taken as $50 \%$ of the peak demand. Similarly, $\mathrm{FG}_{\mathrm{lim}}$ is introduced as the upper limit for purchasing electricity from the grid.

Real time price (RTP) is used for energy interactions with the grid. Cost for system components, grid services are taken considering Sri Lankan context. Market prices used for system components are presented in previous publications of authors [7], [20]. Net present value (NPV) of the system is calculated considering initial capital cost of the system (ICC), present value of fixed annual operation and maintenance costs (FOM), present value of variable annual cash flows for operation and maintenance (VOM) and present value of cash flows for grid interactions (GI) according to Eq. 1.

$$
\mathrm{NPV}=\mathrm{ICC}+F O M \cdot C R F_{c}+\mathrm{GI} \mathrm{CRF}_{\mathrm{GI}}+\sum_{i=1}^{n} V O M_{i} P^{i}
$$

In Eq.1, CRF denotes Capital Recovery Factor and P denote real interest rate. Finally, LEC is calculated using the total energy flows of the system and the NPV.

Similar to LEC, lifecycle emission of the system is modeled. Lifecycle GHG emission of SPV panels, wind turbines and battery bank are taken from Ref. [22]. Life time of SPV panels and wind turbines are considered as the life time of the project. Hence no replacement is considered. 
Replacement of the battery banks are considered in emission calculations. Considering the present Sri Lankan context, $0.412 \mathrm{kgCO} 2 / \mathrm{kWh}$ is taken for emission of grid electricity. Finally, levelized $\mathrm{CO} 2$ emission per $\mathrm{kWh}$ (LCO2) is calculated considering all the flows.

Two Electricity Load Demand (ELD) profiles are taken for the case study. Base curve is taken from Ref. [23] which is presented in Fig. 2. A second ELD profile is generated using the former to introduce more fluctuations to the ELD (Case 2).

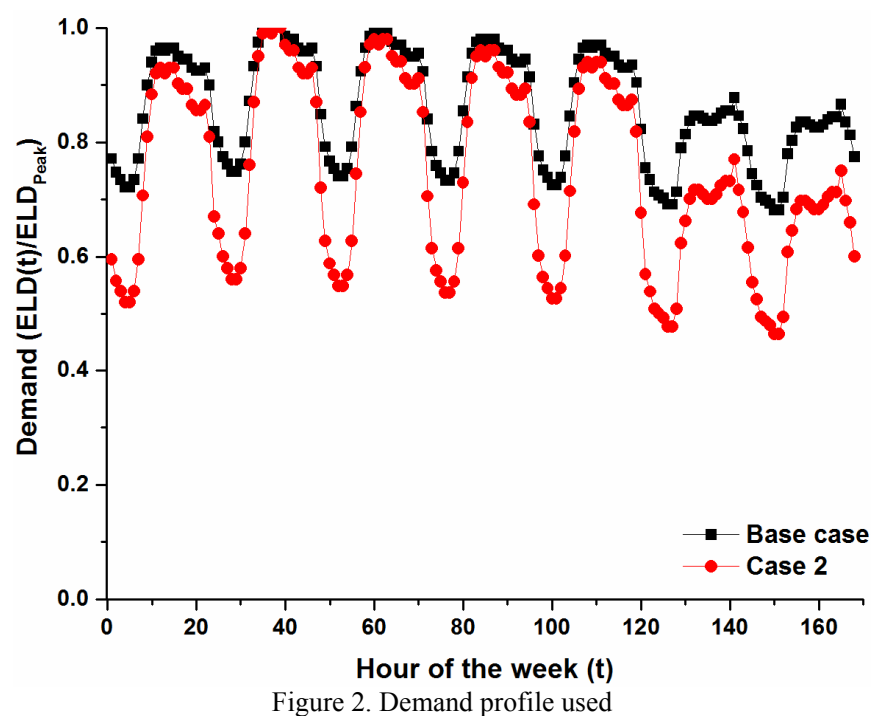

III. ENERGY MANAGEMENT SYSTEM

A novel dispatch strategy is introduced in this work which considers RTP in the grid, SOC of the battery bank, grid curtailments, renewable energy generation and demand of the electrical hub when determining the operating state. The system operates in four main states when renewable energy generation is less than the demand. These states are schematically presented in Fig. 3. In such instances, the demand mismatch can be either taken from the battery bank or grid considering the cost of energy in the utility grid which corresponds to first two states. Critical cost for this (CCFG) is calculated using the optimization algorithm, above which it is economical to use the battery bank. Life time of the lead acid batteries used for the design depends on the depth of discharge. Hence, minimum SOC $\left(\mathrm{SOC}_{\min }\right)$ for discharging process needs to be optimized. When cost of electricity in the utility grid is extremely cheap it can be used to charge batteries in addition to providing the mismatch. The critical cost of energy (CGTB) in the utility grid, which defines this state is optimized using the optimization algorithm. Charging the battery bank using grid electricity will limit the renewable energy generated in future. Hence, it is important to introduce a set point for the battery charging process $\left(\mathrm{SOC}_{\mathrm{SET}}\right)$. Similarly, when cost of electricity is very high in the utility grid it might be profitable to sell electricity discharging the battery bank in addition to catering the mismatch. The critical cost for this state is optimized similarly (CBTG). Similar to $\mathrm{SOC}_{\min }$, minimum SOC is introduced for discharging battery bank to sell electricity to the grid ( $\left.\mathrm{SOC}_{\mathrm{Min} \text { Grid }}\right)$.

Four main states are defined, for instances when renewable energy generation is greater than the demand as shown in Fig. 4. Dispatch strategy for these states can be described in a similar way.

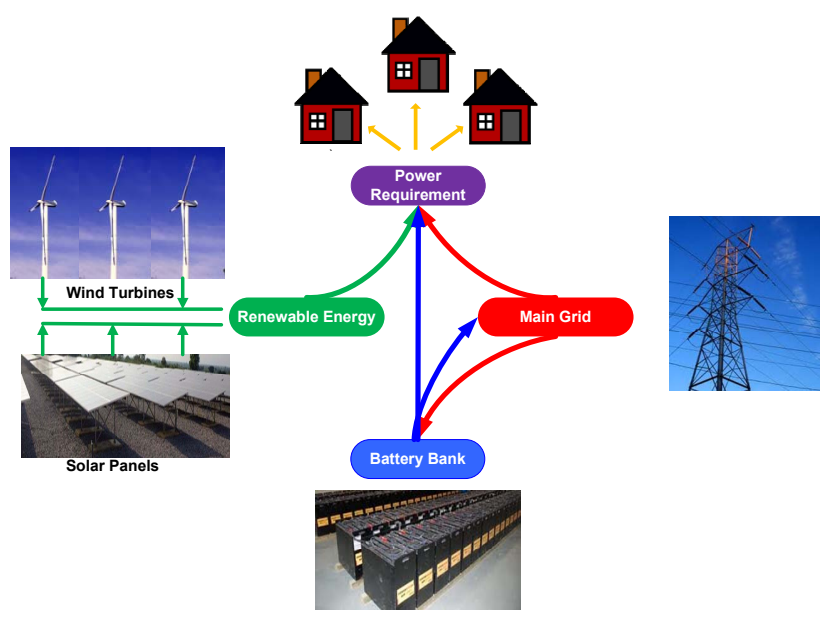

Figure 3. Energy flow options when renewable energy generation is not sufficient to cater the demand

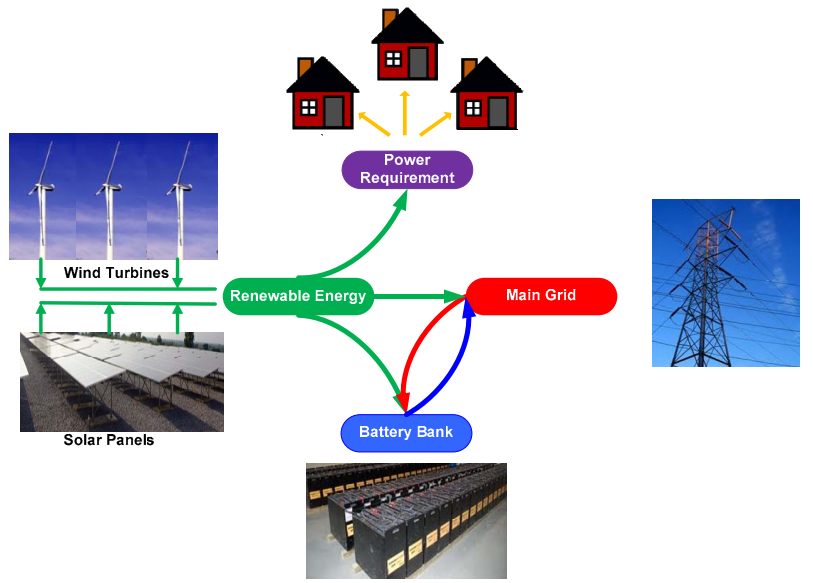

Figure 4. Energy flow options when renewable energy generation is in excess to the demand

\section{DESIGN OPTIMIZATION}

Optimization algorithm is used to obtain optimum system design and energy management strategy. Mapping of decision space variables (Fig. 5) into objective space is not straightforward. A life cycle simulation of the system is required considering hourly fluctuation of demand, renewable energy potential, and cost of energy in grid. Objective functions derived using the lifecycle simulations are neither linear nor analytical. Hence, evolutionary algorithms become more appropriate to be used. A flow chart presentation of the optimization algorithm is given in Fig. 6. Decision space variables are selected as presented in Fig. 5 covering both system design parameters and dispatch strategy. A detailed 
description about the operators used for the optimization is illustrated in detail in Ref. [21]

\begin{tabular}{|c|c|c|c|c|c|c|}
\hline SPV Type & $\begin{array}{c}\text { No. of SPV } \\
\text { Panels }\end{array}$ & $\begin{array}{c}\text { Wind Turbine } \\
\text { Type }\end{array}$ & $\begin{array}{c}\text { No. of Wind } \\
\text { Turbine }\end{array}$ & $\begin{array}{c}\text { No. of Battery } \\
\text { banks }\end{array}$ \\
\hline SOC $_{\text {SET }}$ & SOC $_{\text {Min-Grid }}$ & SOC $_{\text {Min }}$ & CGTB & CCTG & CCTB & CBTG \\
\hline
\end{tabular}

Figure 5. Decision space vectors taken for optimization considering system design and dispatch strategy

\section{RESUlT AND DisCUSSION}

Integration of renewable energy sources into the electrical hub and the optimum selection of dispatchable storage size depend upon a number of factors including cost of power unit and its variation with time, constraints for energy transfer between main-grid and micro-grid, etc. Improvements in LCO2 play a vital role along with LEC in the renewable energy integration process.

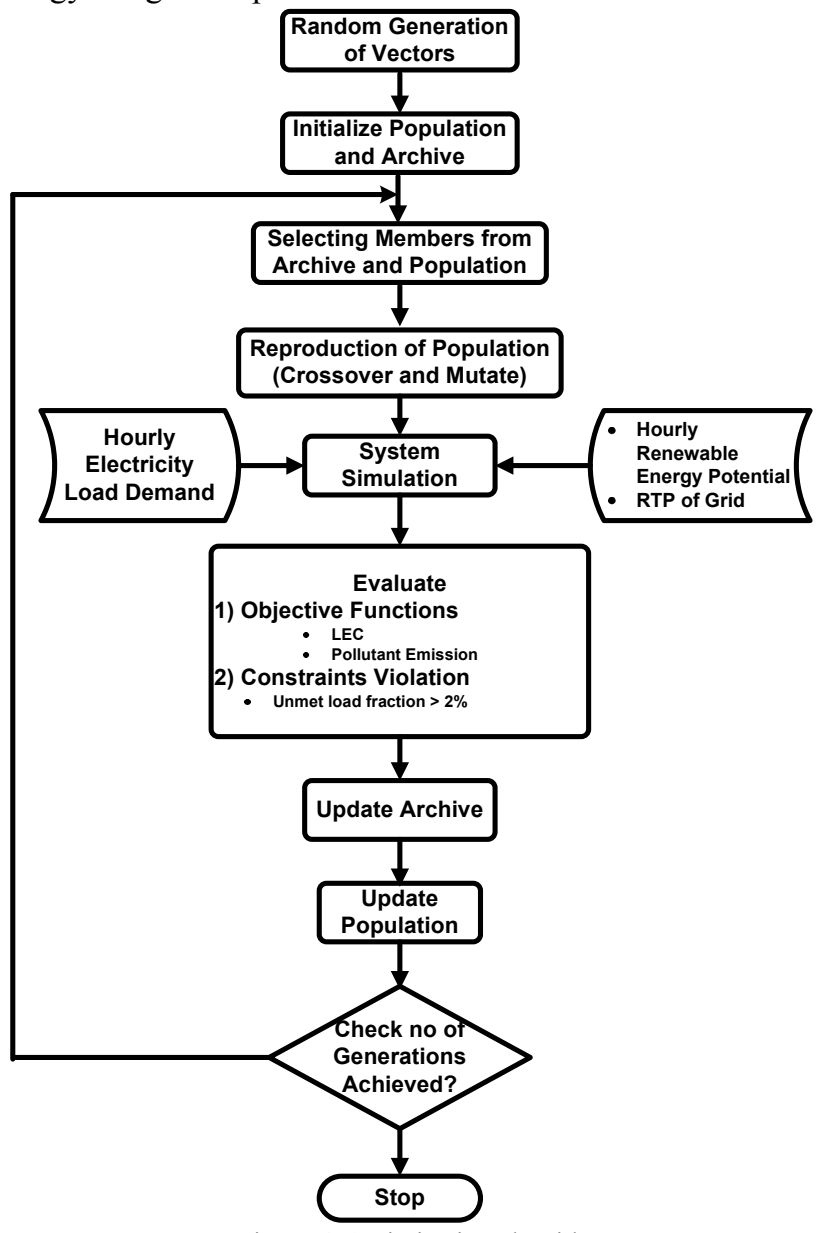

Figure 6. Optimization algorithm

Pareto front obtained considering LEC and LCO2 is presented in Fig. 7. When analyzing the Pareto front, first four solutions can be separated from the rest of the Pareto front as a cluster. A notable reduction in LEC can be observed when moving to the rest of the design solutions. When considering the whole Pareto front, LEC varies from $0.283 \$$ to $0.192 \$$ and $\mathrm{LCO} 2$ varies from $0.10 \mathrm{~kg} / \mathrm{kWh}$ to
$0.19 \mathrm{~kg} / \mathrm{kWh}$. More importantly when we consider the worst case from emission perspective, it is $50 \%$ less than the present $\mathrm{CO} 2$ emission by grid electricity with a significant price reduction in LEC. Furthermore, when considering the system autonomy, $39 \%$ of the energy demand is taken using the grid for the system which is having lowest LEC. This reduces up to $9 \%$ when moving into a system designed with the lowest emission. However, negative point related to these design solutions is the Waste of Renewable Energy (WRE) either due to grid curtailments or limitations in energy storage will increases from $16 \%$ to $64 \%$ when moving from minimum LEC solution to minimum LCO2 emission solution.

In order to analyze the Pareto front further, six Pareto solutions were taken and tabulated in Table 1, 2. Performance indicators and the design configuration of these systems are presented in Table 1 and the control variables for operation strategy are presented in Table 2. As it is observed in Table 1, the Electrical hub tends to purchase more electricity from utility grid. In addition, capacity of PV panels and storage capacity reduces gradually when minimizing LEC. When considering the design parameters, it is observed that minimum SOC for discharging almost reach the minimum state of charge which was set at $30 \%$. Maximum SOC set for charging the battery bank using grid electricity varies from $43 \%$ to $76 \%$. However, when considering the critical cost below which the electricity should be purchased from grid for A1, it is clear that the state exist very rarely since the critical grid cost is goes lower than $0.001 \$$ very rarely. Maximum state of charge limit gradually increases for the rest of the design solutions when moving from A2 to A6.

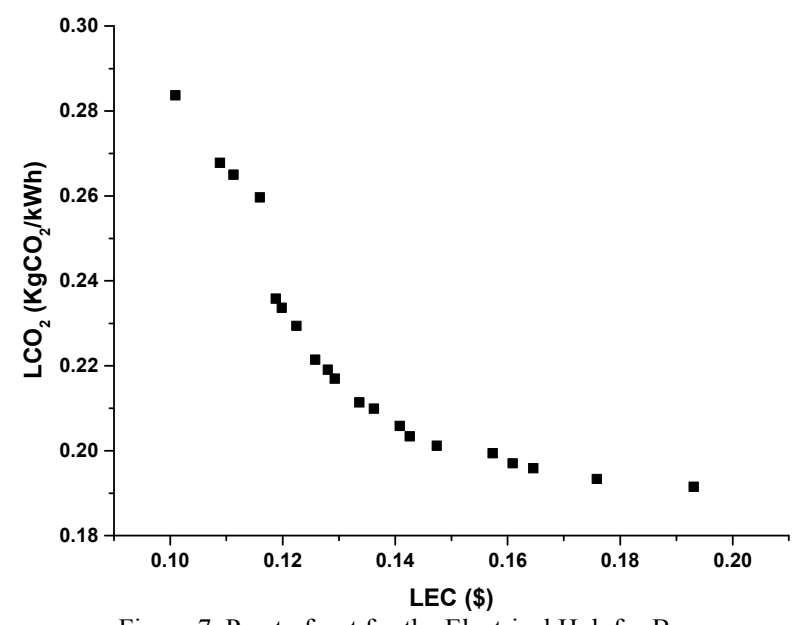

Figure 7. Pareto front for the Electrical Hub for Base case

Energy interactions with the grid play a major in minimizing both operation cost and $\mathrm{CO} 2$ emission. When analyzing the operating states of the optimized energy management system, directing excess generated towards the grid and discharging the battery bank to sell electricity to grid do not exist. Critical limits for CCTG and CBTG are equal to the maximum cost of energy in the grid. This shows that directing excess generated to grid instead of battery charging or discharging battery bank to sell electricity to grid does not take place. 
TABLE I. PERFORMANCE INDICATORS AND SYSTEM CONFIGURATIONS OF SELECTED SIX PARETO SOLUTIONS

\begin{tabular}{|c|c|c|c|c|c|c|c|c|}
\hline System & LEC (\$) & $\begin{array}{c}\text { Emission } \\
(\mathrm{kg} \\
\text { CO2/kWh) }\end{array}$ & TG (\%) & FG (\%) & WRE (\%) & $\begin{array}{c}\text { PV size } \\
(\mathrm{kW})\end{array}$ & $\begin{array}{c}\text { Wind } \\
\text { size (kW) }\end{array}$ & $\begin{array}{c}\text { Battery } \\
(\mathrm{kWh})\end{array}$ \\
\hline A1 & 0.265 & 0.111 & 15.27 & 13.18 & 53.98 & 29 & 23 & 240 \\
\hline A2 & 0.236 & 0.119 & 16.22 & 17.14 & 45.93 & 22.25 & 29 & 180 \\
\hline A3 & 0.229 & 0.122 & 15.44 & 18.39 & 41.70 & 21.75 & 27 & 180 \\
\hline A4 & 0.210 & 0.136 & 13.04 & 22.96 & 29.88 & 20.25 & 21 & 168 \\
\hline A5 & 0.199 & 0.157 & 12.07 & 29.58 & 21.24 & 17 & 19 & 144 \\
\hline A6 & 0.193 & 0.176 & 9.83 & 34.80 & 14.44 & 16.75 & 13 & 144 \\
\hline
\end{tabular}

TABLE II. OPTIMUM PARAMETER SETTINGS FOR OF

\begin{tabular}{|r|c|c|r|r|r|r|}
\hline & $\begin{array}{c}\text { SOC } \\
\text { min }\end{array}$ & $\begin{array}{c}\text { SOC } \\
\text { SET }\end{array}$ & CCTG & CBTG & CCFG & CGBT \\
\hline A1 & 30 & 76 & 0.4 & 0.4 & 0.084 & 0.001 \\
\hline A2 & 31 & 43 & 0.4 & 0.4 & 0.192 & 0.190 \\
\hline A3 & 31 & 55 & 0.4 & 0.4 & 0.204 & 0.184 \\
\hline A4 & 32 & 57 & 0.4 & 0.4 & 0.280 & 0.255 \\
\hline A5 & 30 & 54 & 0.4 & 0.4 & 0.360 & 0.266 \\
\hline A6 & 31 & 64 & 0.4 & 0.4 & 0.38 & 0.243 \\
\hline
\end{tabular}

However, the power units sold to the grid are more than $10 \%$ of the annual demand and sometime reach $34 \%$ (A6). System tends to interact with grid when excess generated is directed to the battery bank through the energy management system and battery bank is at its maximum capacity where excess is directed to the grid.

When considering the purchasing from the grid, a notable change can be observed when moving from system A1 to A6. Critical cost for grid below which it is economical to purchase electricity from grid gradually increases with the reduction of LEC when moving from A1 to A6. When considering A5 and A6 design solutions it is preferred to move to grid instead of taking the mismatch from battery bank. Hence, it can be concluded that the main contribution of battery bank is to limit the $\mathrm{LCO} 2$.

In order to analyze the sensitivity of ELD profile, Pareto front of LEC-LCO2 for Case 2 is taken. Both Pareto fronts are presented in Fig. 8. When analyzing the Pareto fronts a notable reduction in $\mathrm{LCO} 2$ is observed.

\section{CONCLUSIONS}

Electrical hubs can play a major role in integrating nondispatchable renewable energy technologies. A research gap is highlighted to design electrical hubs considering both system design and control strategy especially considering multiple objectives such as LEC and LCO2. Optimum results obtained from the Pareto optimization considering LEC and $\mathrm{LCO} 2$, depict that electrical hubs can minimize the $\mathrm{LCO} 2$ emission for more than $50 \%$ in the Sri Lankan context while minimizing the LEC of the system significantly. When analyzing the control strategy further, it is observed that battery bank plays a major role by actively participating in the energy management in reducing LCO2.

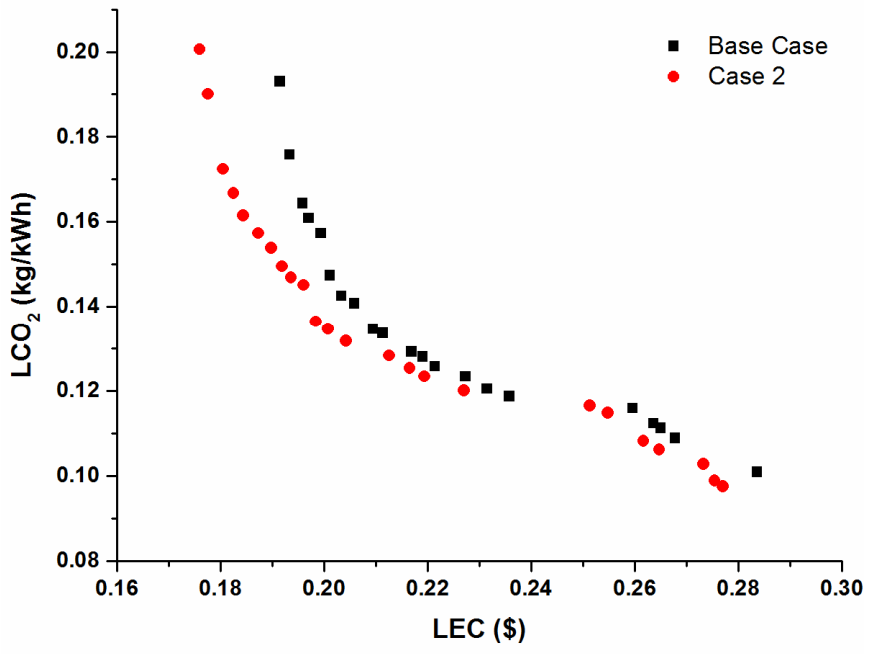

Figure 8. Comparison of two Pareto fronts for Base case and Case 2

\section{REFERENCES}

[1] G. Sansavini, R. Piccinelli, L. R. Golea, and E. Zio, "A stochastic framework for uncertainty analysis in electric power transmission systems with wind generation," Renew. Energy, vol. 64, pp. 71-81, Apr. 2014.

[2] F. Ueckerdt, R. Brecha, G. Luderer, P. Sullivan, E. Schmid, N. Bauer, D. Böttger, and R. Pietzcker, "Representing power sector variability and the integration of variable renewables in long-term energy-economy models using residual load duration curves," Energy, vol. 90, Part 2, pp. 1799-1814, Oct. 2015.

[3] M. Rouholamini and M. Mohammadian, "Energy management of a grid-tied residential-scale hybrid renewable generation system incorporating fuel cell and electrolyzer," Energy Build., vol. 102, pp. 406416, Sep. 2015.

[4] S. M. Sichilalu and X. Xia, "Optimal energy control of grid tied PV-diesel-battery hybrid system powering heat pump water heater," Sol. Energy, vol. 115, pp. 243-254, May 2015.

[5] G. Mavromatidis, K. Orehounig, and J. Carmeliet, "Evaluation of photovoltaic integration potential in a village," Sol. Energy.

[6] F. F. Yanine and E. E. Sauma, "Review of grid-tie microgeneration systems without energy storage: Towards a new approach to sustainable hybrid energy systems linked to energy efficiency," Renew. Sustain. Energy Rev., vol. 26, pp. 60-95, Oct. 2013. 

Dassanayake, "Designing standalone hybrid energy systems minimizing initial investment, life cycle cost and pollutant emission," Energy, vol. 54, pp. 220-230, Jun. 2013.

[8] A. T. D. Perera, R. A. Attalage, K. K. C. K. Perera, and V. P. C. Dassanayake, "A hybrid tool to combine multi-objective optimization and multi-criterion decision making in designing standalone hybrid energy systems," Appl. Energy, vol. 107, pp. 412-425, Jul. 2013.

[9] R. Dufo-López, J. L. Bernal-Agustín, J. M. Yusta-Loyo, J. A. Domínguez-Navarro, I. J. Ramírez-Rosado, J. Lujano, and I. Aso, "Multiobjective optimization minimizing cost and life cycle emissions of standalone PV-wind-diesel systems with batteries storage," Appl. Energy, vol. 88, no. 11, pp. 4033-4041, Nov. 2011.

[10] M. Fadaee and M. A. M. Radzi, "Multi-objective optimization of a stand-alone hybrid renewable energy system by using evolutionary algorithms: A review," Renew. Sustain. Energy Rev., vol. 16, no. 5, pp. 3364-3369, Jun. 2012.

[11] A. T. D. Perera, R. A. Attalage, and K. K. C. K. Perera, "Multi Objective Optimization of Lifecycle Cost, Unmet Load, and Renewable Energy Capacity for an Expansion of Existing Standalone Internal Combustion Generator (ICG) Systems," pp. 1433-1440, Jan. 2011.

[12] A. T. D. Perera, D. M. I. J. Wickremasinghe, D. V. S. Mahindarathna, R. A. Attalage, K. K. C. K. Perera, and E. M. Bartholameuz, "Determining wind turbine capacity for expansion of off grid Internal Combustion Generators (ICG) system; why it bec o mes challenging?," in 2010 IEEE International Conference on Sustainable Energy Technologies (ICSET), 2010, pp. 1-5.

[13] A. T. D. Perera, R. A. Attalage, and K. K. C. K. Perera, "Optimal design of a grid connected hybrid electrical energy system using evolutionary computation," in 2013 8th IEEE International Conference on Industrial and Information Systems (ICIIS), 2013, pp. 12-17.

[14] J. L. Bernal-Agustín and R. Dufo-López, "Hourly energy management for grid-connected wind-hydrogen systems," Int. J. Hydrog. Energy, vol. 33, no. 22, pp. 6401-6413, Nov. 2008.

[15] R. Dufo-López, "Optimisation of size and control of gridconnected storage under real time electricity pricing conditions," Appl. Energy, vol. 140, pp. 395-408, Feb. 2015.

[16] W. Durisch, B. Bitnar, J.-C. Mayor, H. Kiess, K. Lam, and J. Close, "Efficiency model for photovoltaic modules and demonstration of its application to energy yield estimation," Sol. Energy Mater. Sol. Cells, vol. 91, no. 1, pp. 79-84, Jan. 2007.

[17] S. Diaf, D. Diaf, M. Belhamel, M. Haddadi, and A. Louche, "A methodology for optimal sizing of autonomous hybrid PV/wind system," Energy Policy, vol. 35, no. 11, pp. 5708-5718, Nov. 2007.

[18] S. D. Downing and D. F. Socie, "Simple rainflow counting algorithms,” Int. J. Fatigue, vol. 4, no. 1, pp. 31-40, Jan. 1982.

[19] A. T. D. Perera, D. M. I. J. Wickremasinghe, D. V. S. Mahindarathna, R. A. Attalage, K. K. C. K. Perera, and E. M. Bartholameuz, "Sensitivity of internal combustion generator capacity in standalone hybrid energy systems," Energy, vol. 39, no. 1, pp. 403-411, Mar. 2012.

[20] A. T. D. Perera, A. N. Madusanka, R. A. Attalage, and K. K. C. K. Perera, "A multi criterion analysis for renewable energy integration process of a standalone hybrid energy system with internal combustion generator," J. Renew. Sustain. Energy, vol. 7, no. 4, p. 043128, Jul. 2015.

[21] A. T. D. Perera, R. A. Attalage, K. K. C. K. Perera, and V. P. C. Dassanayake, "Converting existing Internal Combustion Generator (ICG) systems into HESs in standalone applications," Energy Convers. Manag., vol. 74 , pp. 237-248, Oct. 2013.

[22] R. Dufo-López, J. L. Bernal-Agustín, J. M. Yusta-Loyo, J. A. Domínguez-Navarro, I. J. Ramírez-Rosado, J. Lujano, and I. Aso, "Multiobjective optimization minimizing cost and life cycle emissions of standalone PV-wind-diesel systems with batteries storage," Appl. Energy, vol. 88, no. 11, pp. 4033-4041, Nov. 2011.

[23] C. Grigg, P. Wong, P. Albrecht, R. Allan, M. Bhavaraju, R. Billinton, Q. Chen, C. Fong, S. Haddad, S. Kuruganty, W. Li, R. Mukerji, D. Patton, N. Rau, D. Reppen, A. Schneider, M. Shahidehpour, and C. Singh, "The IEEE Reliability Test System-1996. A report prepared by the Reliability Test System Task Force of the Application of Probability Methods Subcommittee," IEEE Trans. Power Syst., vol. 14, no. 3, pp. 10101020, Aug. 1999. 